\title{
ANALYSIS OF N-ACETYLGLUCOSAMINE FROM ENZYMATIC DEGRADATION OF AMORPHOUS CHITIN
}

\author{
N. Herdyastuti* and S. E. Cahyaningrum \\ Department of chemistry Universitas Negeri Surabaya, J1. Ketintang Surabaya 60231, Indonesia \\ *E-mail: nuniekherdyastuti@unesa.ac.id
}

\begin{abstract}
$\mathrm{N}$-Acetylglucosamine is the monomeric unit of the polymer chitin with $(1,4)-\beta$-linkages and the second most abundant carbohydrate after cellulose. The purpose of this study was to analyze $\mathrm{N}$-acetyl glucosamine from enzymatic degradation chitin. The method used is the enzymatic hydrolysis of chitin types amorphous using chitinase from Pseudomonas sp. TNH54. Chitin is a kind of amorphous modified chitin and showed high activity against chitinase. $\mathrm{N}$-acetylglucosamine production optimization has been done with a substrate concentration of $1.2 \%$, enzyme concentration of $0.097 \mathrm{U} / \mathrm{mL}$ and the incubation time of 8 hours. The result of purification with ethanol shows a peak with a retention time of 3.1 and a purity of $96.7 \%$. The result showed that the $\mathrm{N}$-acetyl glucosamine hydrolysis enzymatic is in accordance with the standards. Furthermore, experiments to establish purification of N-Acetylglucosamine by ethanol - acetonitrile provides a fairly high yield with similar properties commercial $\mathrm{N}$-Acetylglucosamine
\end{abstract}

Keywords: Chitin, chitinase, enzymatic degradation, N-Acetylglucosamine, purification.

@ RASĀYAN. All rights reserved

\section{INTRODUCTION}

$\mathrm{N}$-Acetylglucosamine (GlcNAc) is a monosaccharide derivative of glucose and distributed widely throughout the world which can be found in chitin. ${ }^{1}$ In human GlcNAc is the constituent element of proteoglycan and glycosaminoglycan polymer chains (such as hyaluronic acid, sulphate chondroitin and sulphate keratan), which are necessary to repair and maintain healthy cartilage and joint function ${ }^{2}$. GlcNAc generally white crystalline powder has a sweet taste that is used as a sugar substitute and received great attention in the treatment of osteoarthritis ${ }^{3,4}$. GlcNAc is a nutrient, metabolite intermediates and required the function of cells and is a candidate food supplement, as well as treatment in patients with osteoarthritis. ${ }^{5}$ The existence of GlcNAc in the thymus gland also appears to prevent the formation and growth of abnormal cells in the thymus (T-cells), which contribute to autoimmune disorders and skin whitening ${ }^{6,7}$. GlcNAc is synthesized in all organisms. But with aging, incapacitation of proteoglycan gradually progresses and results in senile osteoarthritis that boosted clinical test of glucosamine for the treatment of arthritis and its intake as a dietary supplement. ${ }^{8}$ Based on that show that GlcNAc potential for use in industry because it has many significant applications and has high efficiency.

GlcNAc can be generated from the hydrolysis of chitin both enzymatic and non -enzymatic. Several studies have been done to produce GlcNAc using hydrochloric acid as it has done Bohlmanand Chang ${ }^{6,9}$. The production of GlcNAc enzymatically can produce safer products without causing environmental problems, a method is simple, rapid and reproducible. ${ }^{10}$ Production GlcNAc enzymatic to chitin derivate has been done by Sashiwa and Pichyangkura. ${ }^{11,12}$ Herdyastuti's research to show that using chitin modified can be opening its structure so as to facilitate interaction with the enzyme and produce higher activity. ${ }^{13}$

\section{Material Methods}

\section{EXPERIMENTAL}

GlcNAc were purchased from Sigma while chitin (shrimp shells) were purchased from Rongsheng. Crude extract enzyme was isolated from Pseudomonas $s p$. TNH54 by growing in Luria-Bertani medium

Rasayan J. Chem., 10(1), 226 -233 (2017)

http://dx.doi.org/10.7324/RJC.2017.1011582 
containing chitin. Some chemicals such as a Hydrochloric acid (Merck), acetonitrile, methanol, ethanol, acetone, sodium dodecylsulphate (Merck). All other chemicals were analytical reagent grade.

HPLC (Hewlett-Packard, Series 1050) on a Waters column; using a UV detector $210 \mathrm{~nm}$; speed of $1 \mathrm{~mL} /$ min; injection of $0.1 \mathrm{~mL}$ for measurements were to optimum condition and purity of GlcNAc. FT-IR from Perkin Elmer was used to functional group with wave number $400-4000 \mathrm{~cm}^{-1}$. XRD (Bruker type D8 Advance) measurements were to the crystallinity of GlcNAc and Gas chromatography-mass spectrometry (GCMS-QP2010S) was used for measuring molecule mass relative.

\section{Procedure}

\section{Preparation of amorph Chitin and chitinase enzyme}

Chitin has used the type of amorphous chitin which will then be used as an inducer and substrate. Chitin was then made into a kind of amorphous by dissolving $10 \mathrm{~g}$ of chitin in a mixture of $40 \%$ sodium hydroxide solution and $0.2 \% \mathrm{SDS}$ (which has been cooled to a temperature $4^{\circ} \mathrm{C}$ ). The swelling solution for 1 hour at a temperature $4^{\circ} \mathrm{C}$. The matrix of chitin slurry stored for a night at $-20^{\circ} \mathrm{C}$, then neutralized with Hydrochloric acid 6 N. Furthermore filtered, and washed with a solvent sequence of ethanol, water, ethanol, and acetone.

Chitinase enzyme produced from Pseudomonas sp. TNH54 on Luria-Bertani medium containing $0.1 \%$ chitin type amorphous. Single colonies of Pseudomonas sp. TNH54 were grown in $100 \mathrm{~mL}$ of liquid screening medium containing $0.1 \%$ chitin at room temperature with shaking $120 \mathrm{rpm}$ for 18 hours. Liquid culture was then centrifuged at $8000 \mathrm{xg}$ for 15 minutes at $4^{\circ} \mathrm{C}$ temperature. The supernatant obtained a crude extract of chitinase.

\section{Production and purification of GlcNAc}

GlcNAc were produced by enzymatic hydrolysis from chitin at the optimum condition. $2 \mathrm{~mL}$ of chitin $1.2 \%$ (w/v) dissolved in $200 \mathrm{mM}$ potassium phosphate buffer stirred with a magnetic stirrer and added to $0.5 \mathrm{~mL}$ of the enzyme chitinase. Furthermore incubation for 8 hours at room temperature with shaking speeds of $120 \mathrm{rpm}$. After 8 hours the mixture is placed in boiling water for 5 minutes and cooled to room temperature. The suspension is centrifuged for 10 minutes at a speed of $4000 \mathrm{rpm}$ and the supernatant obtained is GlcNAc.

Purification is done by adding some solvent-based nature of polarity. GlcNAc that has been produced is purified by a variation of solvent: acetone, methanol, ethanol and acetonitrile. The results are determined by HPLC purity, nature characterized by using FT-IR, XRD, and GC-MS.

\section{RESULTS AND DISCUSSION}

Modification of chitin by using detergent (Sodium dodecylsulphate) causes swelling of the chitin structure causing changes in the physical properties of chitin powder. In the kind of amorphous chitin has a radius that is longer than the other types of chitin and an area three times larger than the chitin powder. The data shows that the type of amorphous chitin more open and possible further facilitate interaction with chitinase so that it can provide higher chitinase activity compared to other substrates. ${ }^{13}$

\section{Optimization production of $\mathbf{N}$-acetyl glucosamine}

Optimization results formation of GlcNAcagainst substrate concentration indicates that concentration of $1.2 \%$ chitin can produce $\mathrm{N}$-acetyl glucosamine highest of $22.8 \mathrm{mg} / \mathrm{mL}$ or $94.8 \%$ (Table-1).

Table-1 : Determination of optimum substrate concentration

\begin{tabular}{ccc}
\hline $\begin{array}{c}\text { Concentration of } \\
\text { Substrate }(\%)\end{array}$ & Area (mAU) & N-acetyl glucosamine (mg/mL) \\
\hline 0.4 & 1230 & 1.98 \\
\hline 0.8 & 4190 & 6.39 \\
\hline \multicolumn{3}{c}{227}
\end{tabular}


RASĀYAN $J$. Chem.

Vol. 10 | No. 1 |226 -233 | January - March | 2017

\begin{tabular}{c|c|c}
\hline 1.2 & 15180 & 22.78 \\
\hline 1.6 & 10580 & 15.92 \\
\hline 2.0 & 9820 & 14.79 \\
\hline 2.4 & 2510 & 3.89 \\
\hline
\end{tabular}

Variations in incubation time are generated when the enzyme chitinase and chitin type amorphous with a time of 8 hours in the amount of $10.95 \mathrm{mg} / \mathrm{mL}$ or $45.6 \%$ (Table-2) with an enzyme concentration of 0.1 $\mathrm{U} / \mathrm{mL}$. The number of $\mathrm{N}$-acetyl glucosamine highest in the variation of incubation time is generated when the enzyme chitinase and chitin types of amorphous with a time of 8 hours in the amount of $10.95 \mathrm{mg} / \mathrm{mL}$ or $45.6 \%$. Chitin and chitosan are compounds that are not soluble in water so it is also an obstacle for the enzyme so it takes a long time to degrade. ${ }^{14}$ The number of GlcNAc turns decreased after incubation up to 24 hours. Sukprasert (2014) obtaining $\mathrm{N}$-acetyl glucosamine by $20 \%$ by using chitin substrate $\beta$-types 80 $\mathrm{mg} / \mathrm{mL}$ were incubated for 24 hours. ${ }^{15}$ The decline in the number of GlcNAc may be because enzymes undergo denaturation during the reaction or inhibition occurs during the process of the formation of $\mathrm{N}$ acetylglucosamine. ${ }^{16}$

Table -2 : Determination of incubation time for $\mathrm{N}$-Acetylglucosamine production

\begin{tabular}{ccc}
\hline $\begin{array}{c}\text { Incubation time } \\
\text { (hour) }\end{array}$ & Area (mAU) & $\begin{array}{c}\text { N-acetyl glucosamine } \\
(\mathrm{mg} / \mathrm{mL})\end{array}$ \\
\hline 0 & 214,7 & 0,46 \\
\hline 1 & 681 & 1,16 \\
\hline 2 & 813 & 1,36 \\
\hline 4 & 3203 & 4,92 \\
\hline 6 & 7087 & 10,71 \\
\hline 8 & 7244 & 10,95 \\
\hline 24 & 5472 & 8,31 \\
\hline
\end{tabular}

Accordingto Widyastuti (2007), chitooligosaccharide compounds and GlcNAc hydrolysis of chitin by chitinase in high concentrations can cause feedback inhibition due to an excess of GlcNAc as the final product. ${ }^{4}$ Other studies mention that chitinase may be inhibited competitively by several compounds like alosamidyn and several compounds in addition to sugar contained in it. ${ }^{17}$

\section{Characteristic of N-Acetylglucosamine}

Purification of GlcNAc is done varies by using several solvents and showing retention time equal to GlcNAc standard as in Figure-1. When observed in all four types of solvents showed a similar pattern, with peaks thought to be GlcNAc has a separate well although there is another peak that was not separated and is suspected as oligomers of GlcNAc. The separations of two or more from these substances were based on differences in distribution coefficient. If the solute has a $\mathrm{K}$ value greater than 1 and the other is smaller than 1, then with a single extraction can be separated. However, if the two substances have the same but not identical distribution coefficient, then the separation would only partially separate, so it needs to add another solvent using Craig Lyman. ${ }^{18}$ The result of purification of GlcNAc in each solvent demonstrates sufficient purity as high as 86 to $97.7 \%$.

The existence of a single peak of GlcNAc is also supported by the results of gas chromatography (Figure2).The results of the HPLC purification is supported by data GC which yielded a peak with a retention time of about 15 minutes, indicating that the compound obtained is pure GlcNAc. 
RASĀYAN J. Chem.

Vol. 10 | No. 1 |226-233 | January - March | 2017

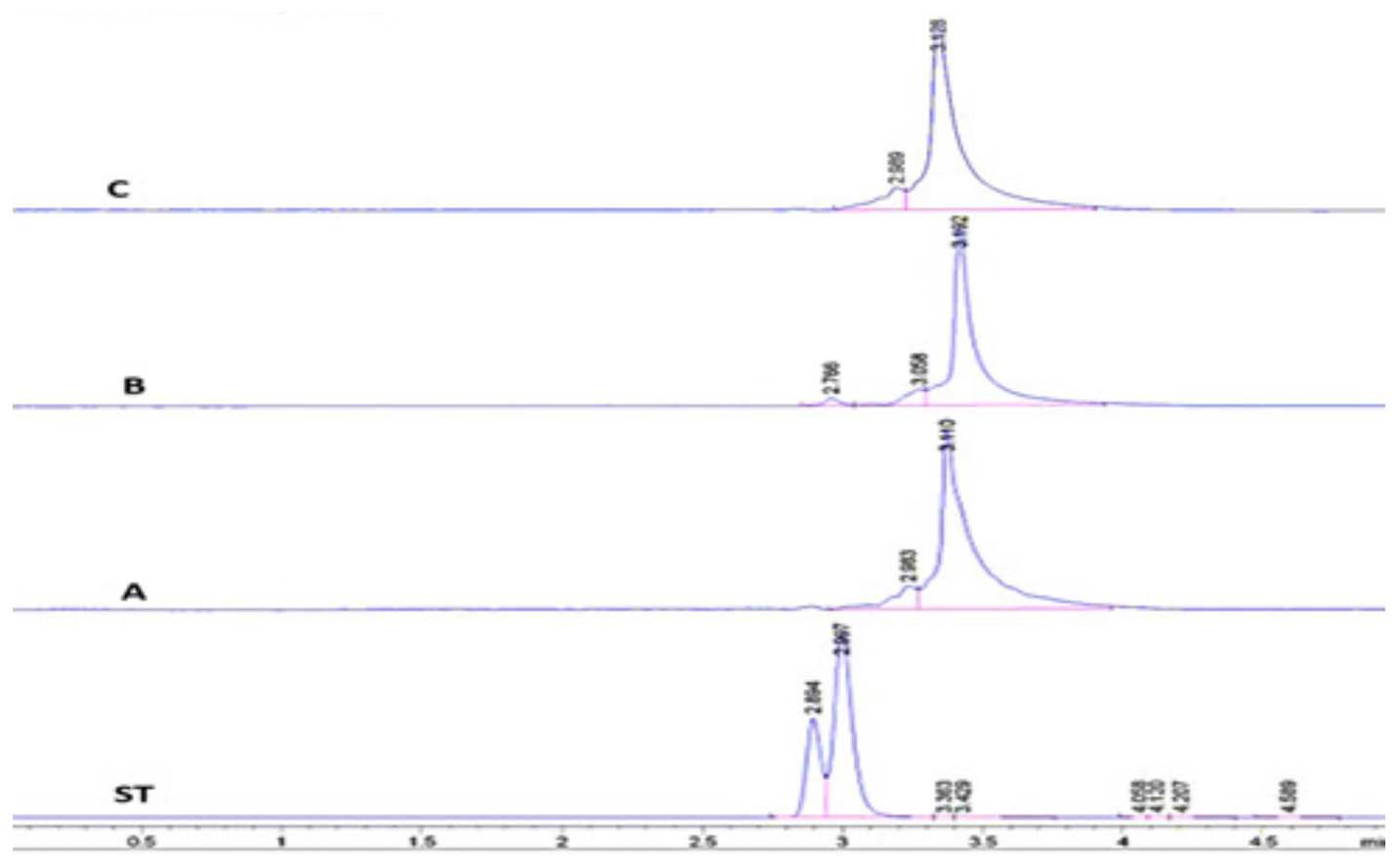

Fig.-1: Purification result of $\mathrm{N}$-acetyl glucosamine with a variety of solvents using ethanol (A), acetone (B), acetonitrile (C), and standard NAG (ST)

(c)

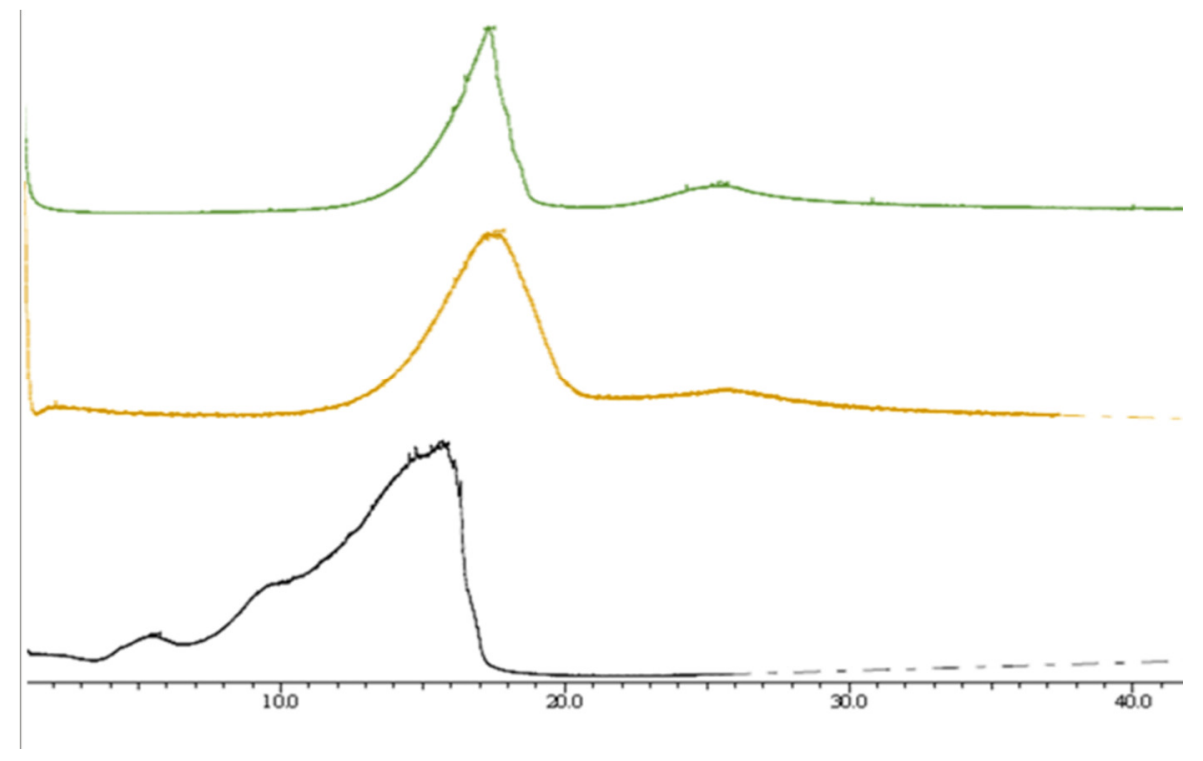

Fig.-2: GC-MS spectra of GlcNAcstandard (a), in ethanol (b)and in methanol (c)

The results of the determination of functional groups on the GlcNAcwith FT-IR also showed a similar pattern to the standard (Figure-3), which are group $\mathrm{O}-\mathrm{Hat}$ about $3500 \mathrm{~cm}^{-1}$, the $\mathrm{C}=\mathrm{O}$ at $1670 \mathrm{~cm}^{-1}, \mathrm{~N}-$ $\mathrm{H}$ at $1329 \mathrm{~cm}^{-1}$ and $\mathrm{C}-\mathrm{Hat} 1378 \mathrm{~cm}^{-1}$ which is a major functional group found in the structure GlcNAc (Figure-4). 


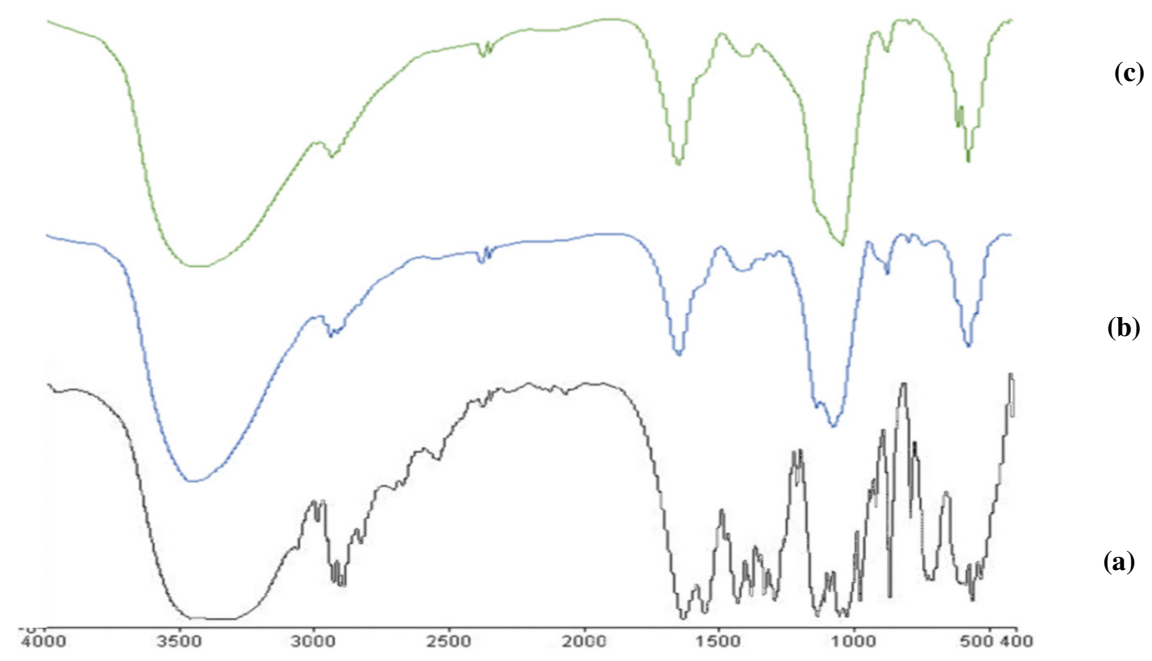

(c)

(b)

(a)

Fig.-3: FTIR spectra of GlcNAcstandard (a), in ethanol (b)and in methanol (c)

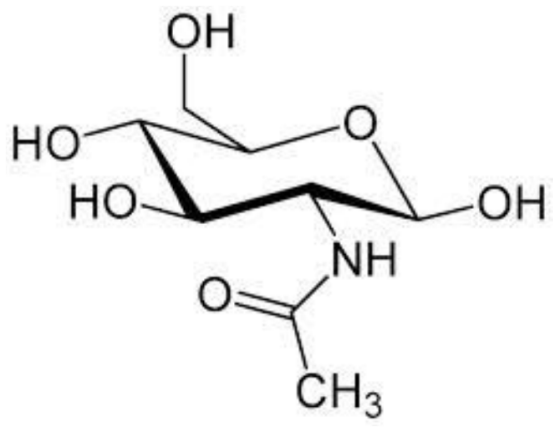

Fig.-4: Structure of N-Acetyl glucosamine

The presence of carbon compounds, nitrogen and oxygen were supported by data SEM-EDS in Figure-5 with a high enough percentage of the $\mathrm{C}, \mathrm{N}$, and $\mathrm{O}$ are the main components of chitin.

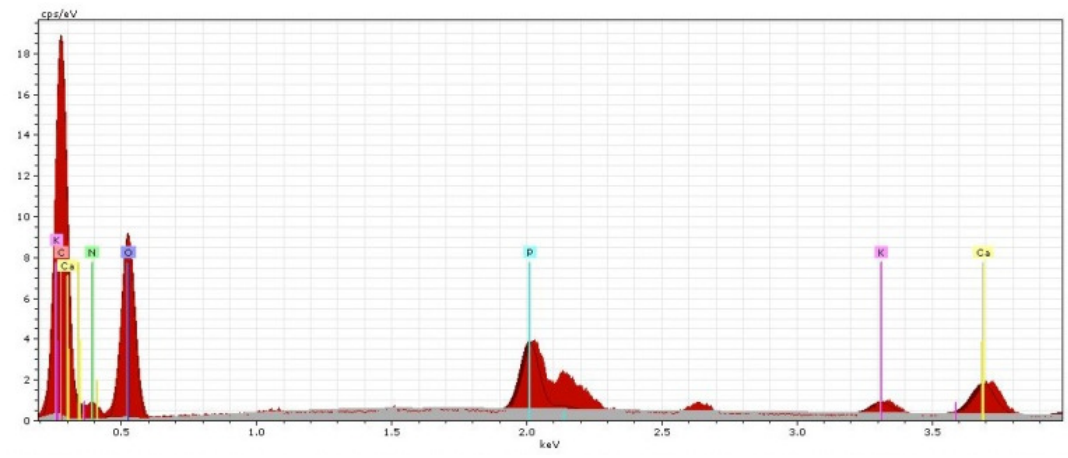

Fig.-5: SEM -EDS analysis of N-Acetyl glucosamine

$\mathrm{N}$-Acetyl Glucosamine is a white crystalline powder that dissolves in water. XRD analysis results prove that $\mathrm{N}$-acetyl glucosamine that has been hydrolyzed enzymatically is a crystalline powder that can be identified at the main summit $2 \theta$ namely 10; 15, 20 and 30 (Figure-6). Based on the calculation of the 
RASĀYAN J. Chem.

Vol. 10 | No. 1 |226 -233 | January - March | 2017

yield of $\mathrm{N}$-acetyl glucosamine obtained still very small at around $11 \%$ of the total initial chitin were used. This is likely because many N-Acetyl glucosamine lost in the refining process. Aiba ,(2002) obtained 66$77 \%$ (mol/mol) N-Acetyl glucosamine from enzymatic degradation of Aeromonashydrophila $\mathrm{H}-2330$ using chitin - $\alpha$ after incubation for 10 days. ${ }^{11}$ Other studies claim that the chitin concentration of $10 \mathrm{~g} / \mathrm{L}$ can produce $\mathrm{N}$-acetyl glucosamine is $0.38 \mathrm{~g} / \mathrm{L}$, or about $3.8 \%$ were incubated for 6 days using colloidal chitin and chitinase enzymes from Trichodermaharzianum MTCC 3928. ${ }^{18}$

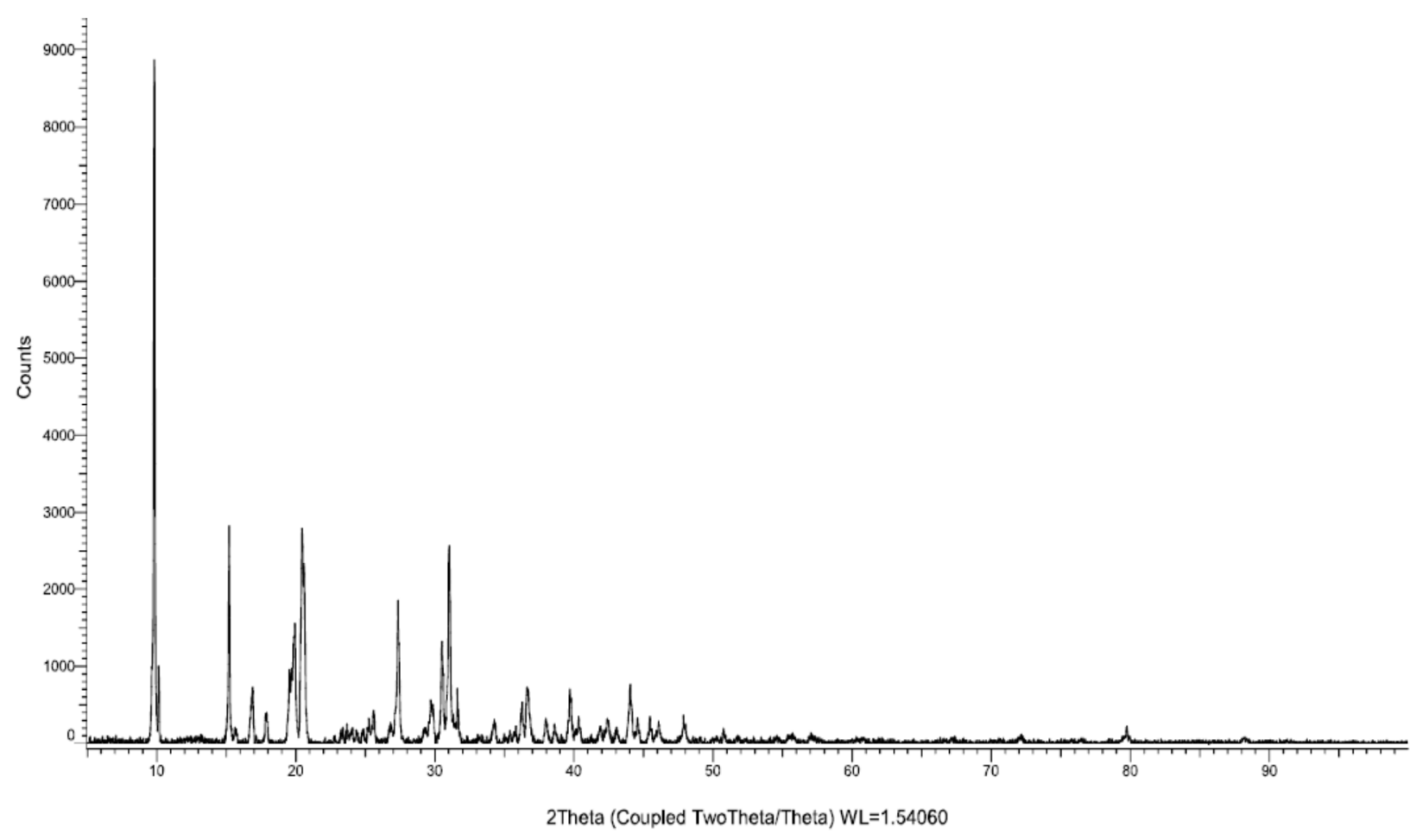

Fig.-6: XRD chromatogram of N-Acetil glucosamine

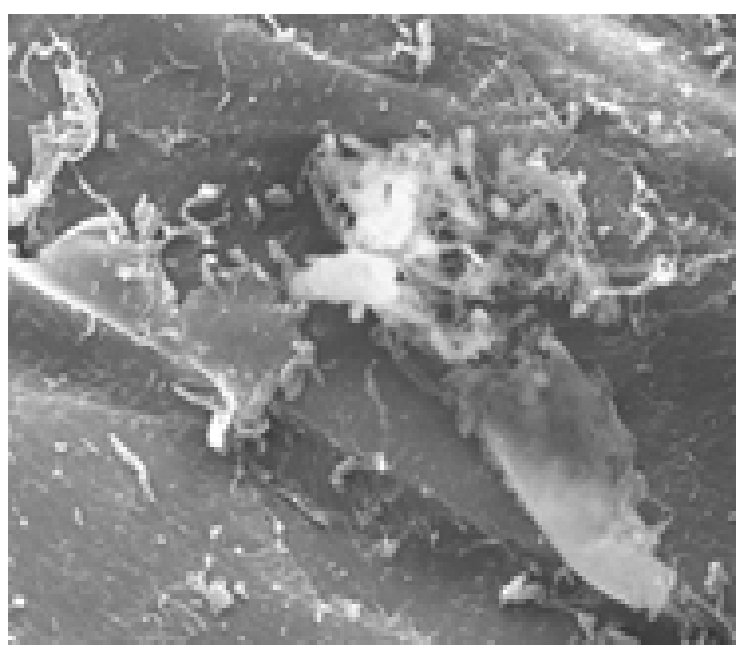

(a)

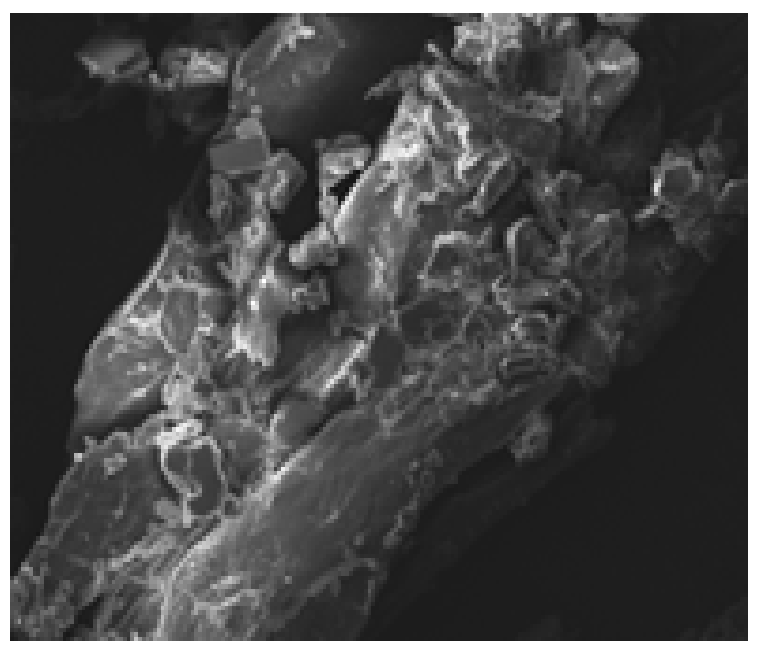

(b) 


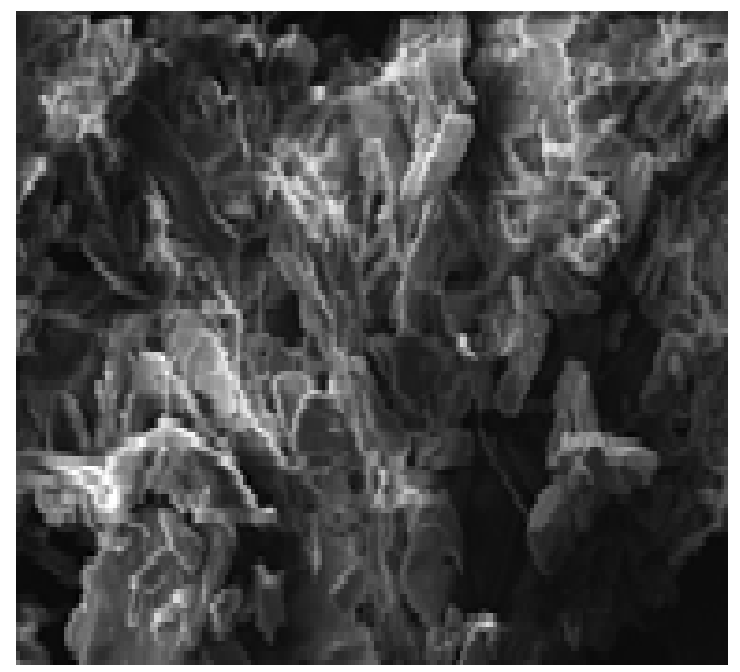

(c)

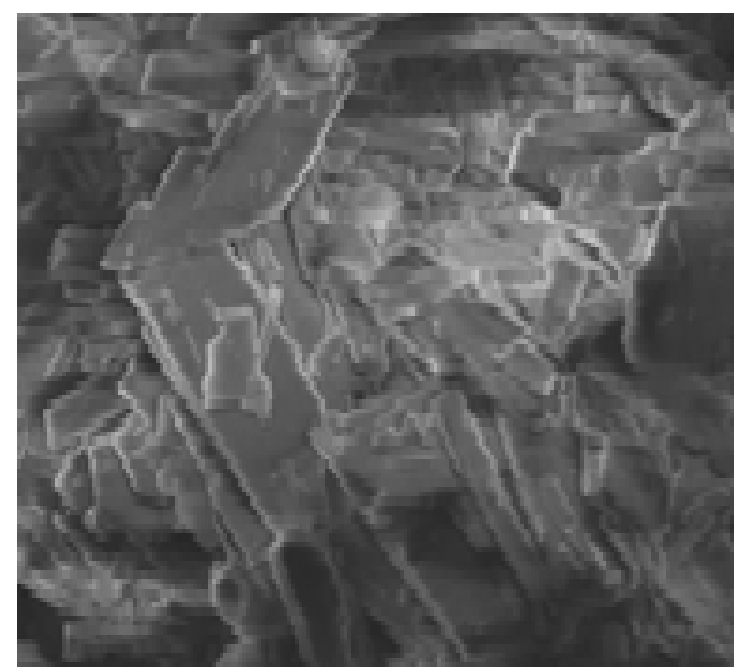

(d)

Fig.- 7: Scanning electron microscope at $2400 \mathrm{X}$ of chitin powder (a), amorph chitin (b), chitin was degradation enzyme (c), and N-Acetyl glucosamine (d)

\section{Morphology of N-Acetylglucosamine from chitin degradation}

Based on morphological observation, the type of amorphous chitin which has been degraded by the enzyme produces pieces which are GlcNAc. The same was said by Uchiyama et al (2011), using Scanning electron the measurement chitin microfibrils which were degraded by chitinase with microscope showed that the morphology of into shorter pieces and have almost the same end, namely $\mathrm{N}$ acetylglucosamine. ${ }^{20}$ Figure-7 shows the change in morphology of chitin powder is very tight. And intermolecular hydrogen bonding between chitin can cause the structure to have a high density so that the chitin into a compact and tight. The structure has changed after the powder chitin modified into an amorphous type (Fig.-7b). Chitin kind of amorphous showed morphology that is more open than the chitin powder so that chitinase is easier to degrade chitin become GlcNAc (Fig.-7c).

The results of GC - MS showed that the compound $\mathrm{N}$-acetyl glucosamine obtained results that fragmentation is dominated by a $\mathrm{m} / \mathrm{z}=43,59,72$ and 130 (Figure-8) that shows the fragmentation of components $\mathrm{N}$-acetyl glucosamine is $\mathrm{CH}_{3}-\mathrm{C}=\mathrm{O}, \mathrm{HNCH}_{3}-\mathrm{C}=\mathrm{O}$ and the possibility of glucose. Based on the results of $\mathrm{m} / \mathrm{z}$ obtained it can be expected that the compounds obtained have molecular weights approaching the molecular mass of $\mathrm{N}$-acetyl glucosamine about $221.1 \mathrm{~g} / \mathrm{mol}$.

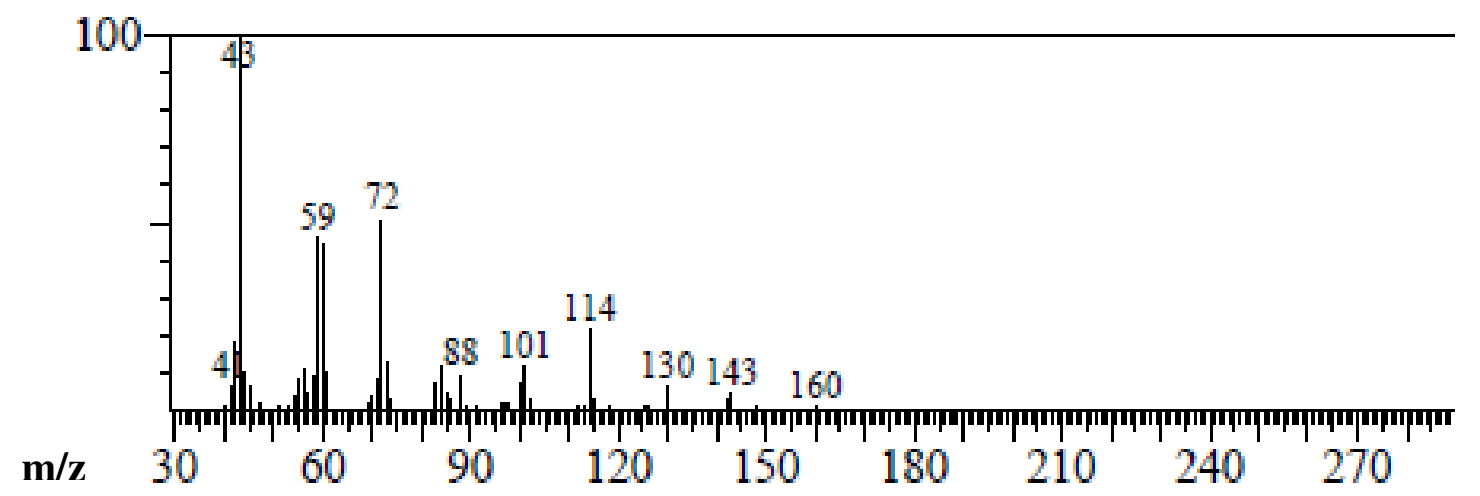

Fig.-8: GC-MS spectra of the N-Acetyl glucosamine The product obtained after a 8 h digestion of chitin using chitinolytic enzymes from Pseudomonas sp. TNH54. 
RASĀYAN $J$. Chem.

Vol. 10 | No. 1 |226-233 | January - March | 2017

\section{CONCLUSION}

The purpose of this work is to analyze GlcNAc from enzymatic hydrolysis chitin by isolation, purification, and characterization. The method used is the enzymatic of chitin type amorphous using chitinase from Pseudomonas sp. TNH54. The result showed that the GlcNAc hydrolysis product was similar properties commercial GlcNAc with a purity of $96.7 \%$. Furthermore, experiments to establish purification of N-Acetyl Glucosamine by ethanol - acetonitrile can be recommended

\section{REFERENCES}

1. J.K. Chen, C.R. Shen and C.L. Liu, Mar. Drugs, 8, 2493 (2010)

2. Y. Tamai, K. Miyatake, Y. Okamoto, Y. Takamori, K. Sakamoto and S. Minami S Carbohyd. Polym.,54, 251 (2003)

3. H. Sashiwa, S. Fujishima, N. Yamano, N. Kawasaki, A. Nakayama, E. Muraki, M. Sukwattanasinitt, R. Pichyangkura and S. Aiba,Carbohydr. Polym.,51,391(2003)

4. Widyastutidan Nunuk, Produksi Kitinase Ekstraseluler, Aspergillusrugulosus 501 Secara Optimal Pada Media Cair, Pusat Penelitian Biologi-LIPI: Cibinong (2007)

5. P. Ilankovan, S. Hein, C.Ng, T.S. Trung, W.F. Carbohydr. Polym., 63, 245 (2006)

6. K.L.B. Chang and W.R.FU, J.of Food and Drug Analysis, 8, 75 (2000)

7. D.L.Bissett, L.R. Robinson, P.S. Raleigh, K. Miyamoto, T. Hakozaki , J. Li and G.R. Kelm, J. Cosmet. Dermatol, 6, 20,(2007)

8. D.S. Hungerford and L.C. Jones, J. Arthroplasty, 18, 5(2003)

9. J.A. Bohlman, D.O. Schisler, K.O. Hwang, J.P. Hennling, J.R. Trinkle, T.B. Anderson, J.D. Steinke and A. Vanderhoff, US Patent 6693188B2 (2004).

10. I.M. Krokeide, V.G.H. Eijsink and M. Sørlie, ThermochimicaActa, 454, 144 (2007)

11. S. Aiba, H.Sashiwa, S. Fujishima, N. Yamano, N. Kawasaki, A. Nakayama, E. Muraki, K. Hiraga, K. Oda, Carbohydrate Research, 337, 761 (2002)

12. R. Pichyangkura, S. Kudan, K. Kuttiyawang, M. Sukwattanasinitt and S. Aiba, Carbohydr. Res.,337, 557(2002)

13. N. Herdaystuti, S.E. Cahyaningrum, M. Tamimi M and A. Wirawan,Afric. J. of Biotech.,14(18), 1590(2015)

14. L.R. Coutiño, M.C. Marı'a del Carmen, S. Huerta, S. Revah, K. Shirai,Proc. Biochem.,41, 1106(2006)

15. P. Sukprasirt and R. Wititsuwannakul, Phytochemistry, 104, 5 (2014)

16. K. Jamialahmadi, J. Behravan, M.F. Najafi, M.T. Yazdi,A.R. Shahverdi, and M.A. Faramarzi, Biotechnology, 10(3), 292 (2011)

17. M.G. Peter, Polysacharides and Polyamides in the Food Industry. , 1.Wernheim: Wiley-VCH(2005)

18. R.L. Pecsok, L.D. Shields, T. Cairns and I.G. McWilliams,. John Willey and sons, New York, p 3037 (1976)

19. G.N. Rameshaiah and Y. Suneetha Intern. J. of Adv. Engin. and Nano Tech. (IJAENT), 2, 22 (2014)

20. T. Uchiyama, F. Katouno, N. Nikaidou, T. Nonaka, J. Sugiyama and T. Watanabe T,The J. of Biol. Chem.,276, 41343 (2001)

[RJC-1582/2017] 